$7-1-2012$

\title{
Transference And Congruence Effects On Purchase Intentions In Online Stores Of Multi-Channel Retailers: Initial Evidence From The U.S. And South Korea
}

Vishag Badrinarayanan

Texas State University - San Marcos, vb16@txstate.edu

Enrique P. Becerra

Texas State University - San Marcos, eb25@txstate.edu

Chun-Hyun Kim

Sogang University, chkim@sogang.ac.kr

Sreedhar Madhavaram

Cleveland State University, s.madhavaram@csuohio.edu

Follow this and additional works at: https://engagedscholarship.csuohio.edu/bus_facpub

Part of the Marketing Commons

How does access to this work benefit you? Let us know!

Publisher's Statement

The final publication is available at Springer via http://dx.doi.org/10.1007/s11747-010-0239-9

Original Published Citation

Badrinarayanan, V., Becerra, E.P., Kim, C., \& Madhavaram, S. (2012). Transference and congruence effects on purchase intentions in online stores of multi-channel retailers: Initial evidence from the U.S. and South Korea. Journal of the Academy of Marketing Science, 40(4), 539-557. doi: 10.1007/s11747-010-0239-9

This Article is brought to you for free and open access by the Monte Ahuja College of Business at EngagedScholarship@CSU. It has been accepted for inclusion in Business Faculty Publications by an authorized administrator of EngagedScholarship@CSU. For more information, please contact library.es@csuohio.edu. 


\title{
Transference and congruence effects on purchase intentions in online stores of multi-channel retailers: initial evidence from the U.S. and South Korea
}

\author{
Vishag Badrinarayanan • Enrique P. Becerra • \\ Chung-Hyun Kim $\cdot$ Sreedhar Madhavaram
}

\begin{abstract}
Drawing from research on retailing, online shopping behavior, and theories of cognitive psychology, we develop and test a framework that investigates purchase intentions in online stores of multi-channel retailers. The framework simultaneously examines the influence of transference of attitude and trust from the multi-channel retailer's physical to online stores, image congruence between the multi-channel retailer's physical and online stores, and image congruence between the multi-channel retailer's online store and a prototypical online store. Further, recognizing that several retailers now operate as multi-channel retailers in different countries, we examine the influence of cultural differences in thought processes
\end{abstract}

All authors contributed equally and are listed in alphabetical order. The authors thank the editor and four anonymous reviewers for their constructive comments. The first two authors acknowledge a grant from the Research Enhancement Program at Texas State UniversitySan Marcos.

V. Badrinarayanan $(\bowtie) \cdot$ E. P. Becerra

McCoy College of Business Administration,

Texas State University - San Marcos,

601 University Drive,

San Marcos, TX 78666, USA

e-mail: vb16@txstate.edu

E. P. Becerra

e-mail: eb25@txstate.edu

C.-H. Kim

Graduate School of Media Communications, Sogang University,

Seoul, South Korea

e-mail: chkim@sogang.ac.kr

S. Madhavaram

Nance College of Business Administration,

Cleveland State University,

Cleveland, OH 44115, USA

e-mail: s.madhavaram@csuohio.edu (i.e., holistic versus analytic thinking) on shoppers' evaluation of online stores of multi-channel retailers. Toward this end, we test the framework using data collected from respondents in the U.S. (analytic thinkers) and South Korea (holistic thinkers). We conclude with a discussion of the findings, suggestions for future research, and potential limitations.

Keywords Multi-channel retailing - Online purchase intentions · Trust and attitude transference - Image congruence $\cdot$ Analytic versus holistic thinking styles

\section{Introduction}

In the last decade or so, a majority of erstwhile traditional retailers have transformed into multi-channel retailers by establishing an online presence. ${ }^{1}$ For instance, multichannel retailers now account for approximately forty percent of Internet Retailer's top 500 largest online retailers (Internet Retailer 2010) and fifty percent of the National Retail Federation's list of top 50 favorite online retailers (National Retail Federation 2010). Nonetheless, online stores of multi-channel retailers continue to underperform on shoppers' purchase intentions compared to online stores of pure Internet players (Nielsen/NetRatings 2005). As a result, researchers have emphasized that multi-channel retailers need to better understand online consumer behavior to compete more effectively against pure Internet retailers (Konus et al. 2008; Rigby 2007).

\footnotetext{
${ }^{1}$ Although, more recently, online retailers have established land-based stores, we limit our focus to land-based retailers who transition into multi-channel retailers by establishing their own online stores.
} 
However, for multi-channel retailers, effective management of customer perceptions is quite complex as it entails managing shoppers' existing attitudes and beliefs carried over from prior experiences with their physical stores as well as the emergent expectations based on the online retail environment (Kwon and Lennon 2009a, b). Correspondingly, past studies have leveraged research on brand extensions (e.g., Aaker and Keller 1990) to examine perceived congruence between a multi-channel retailer's physical and online stores and the subsequent transference of attitudes and beliefs between the stores. But, shoppers' evaluations of online stores of multi-channel retailers may include multiple frames of reference, including the multichannel retailer's physical store and other prototypical online stores. For instance, leading online stores have clearly established category standards in terms of product assortment, delivery terms and schedules, customer service, product recommendations and user reviews, and payment options, among others. Unfortunately, existing theoretical frameworks on purchase intentions in online stores of multi-channel retailers have not addressed the simultaneous impact of factors related to the physical and online stores of the multichannel retailer as well as prototypical online stores.

In addition, a particularly noteworthy trend in retailing is the increase in the number of multi-channel retailers who maintain physical and online stores for retail transactions in different countries (e.g., IKEA, H\&M, Tesco, Walmart). Yet, several global retailing powerhouses have struggled to compete effectively against well-entrenched local multichannel retailers (e.g., Carrefour, Tesco, and Walmart versus Lotte and Shinsegae in South Korea; Walmart versus Aeon's Jusco in Japan). As retailers expand across geographic borders, they need to identify strategies that enable them to compete successfully in local markets. A growing body of research suggests that cultural differences influence shoppers' attitudes toward online stores (Jarvenpaa and Tractinsky 1999) and that trans-cultural online stores may not be appropriate when cultural differences exist (Lee et al. 2007). In the context of brand extensions, Monga and John (2007) find that cultural differences in thought processes influence consumers' acceptance of brand extensions with holistic thinkers (e.g., East Asian cultures) evaluating brand extensions more favorably than analytic thinkers (e.g., Western cultures). Given that online stores of multi-channel retailers are construed as extensions of traditional retailers into the online retail environment, the acceptance of the online stores may depend on shoppers' thinking styles that shape inductive inferences regarding the store. Therefore, an understanding of cultural differences in shoppers' thinking styles would enable multi-channel retailers to decide whether or not to signal associations between their physical and online stores, as well as, with online stores that are construed as exemplars in local markets. Indeed, due to differences in information processing styles, marketing and brand communication strategies that are successful in the U.S. may not perform well in Asian countries like South Korea and India (Alden et al. 1999; Suri et al. 2004). Consequently, as it is imperative for multichannel retailers to develop strategies that account for marketplace diversity across international markets, we also examine the influence of cultural differences in thought processes on shoppers' evaluation of online stores of multichannel retailers.

Stated explicitly, the objectives of this study are as follows. First, we examine whether perceptions of congruence between a multi-channel retailer's physical and online stores influence the transference of attitudes and trust between the two stores. Second, we examine whether perceptions of congruence between a multi-channel retailer's online store and a prototypical online store influence attitudes and trust toward the multi-channel retailer's online store. Third, we explore whether differences in consumers' informational processing styles (i.e., thinking tendencies) influence the effects of congruence and transference on purchase intentions in online stores of multi-channel retailers.

To fulfill these objectives, we develop and test a framework of purchase intentions in online stores of multi-channel retailers that simultaneously examines shoppers' assessments of a multi-channel retailer's online store, transference of attitudes and beliefs from the multi-channel retailer's physical store, perceived congruence with the parent physical store, and perceived congruence with a prototypical online store. From a theoretical standpoint, the framework advances knowledge on purchase intentions in multi-channel retailers' online stores by integrating insights from the retailing, brand extension, and thinking tendencies literatures. From a practical standpoint, the study offers insights on how multi-channel retailers could manage purchase intentions in their online stores by facilitating the transfer of beliefs and attitudes across their store formats and by possessing characteristics that are idiosyncratic to the online retail environment. Finally, consistent with our objective to test for the influence of differences in thinking tendencies across cultures, an important contribution of this study is embedded in the cross-national comparison of the framework using data gathered from respondents from the United States (U.S.) and South Korea (S. Korea).

The remainder of the paper is organized as follows. Building on the literature on multi-channel retailers, we develop the theoretical framework and present hypotheses. Next, drawing from and extending research on the influence of differences in thinking styles, we examine how the proposed relationships vary across holistic and analytic thinkers. Concomitantly, we also elaborate on why the U.S. and S. Korea were chosen as focal countries for 
our study on multi-channel retailers. Finally, following discussions on the methodology, analyses, and results, we elaborate on our findings and conclude with a summary of future research directions and potential limitations.

\section{Theoretical framework and hypotheses}

Research on traditional retailers who have migrated to the multi-channel format is sparse and fragmented. Some studies in this domain have focused on the operational integration of retailers' physical and online stores or the design elements of retail stores in online environments (e.g., Barnes et al. 2004; Ranganathan et al. 2003). The importance of attitude, trust, and shopping quality perceptions associated with online retail stores have been extensively studied (e.g., Ha and Stoel 2009; Jarvenpaa and Tractinsky 1999). More recently, construing traditional retailers' transformation to multi-channel retailers as analogous to brand extensions, researchers (Kwon and Lennon 2009a, b; Wang et al. 2009) have examined how retail shoppers carry forward their evaluations from multi-channel retailers' physical stores to online stores. Taken together, these studies broadly suggest that multi-channel retailers must formulate their online strategies by considering customers' perceptions and beliefs that are both (1) formed as a result of exposure to the retailer's online store and (2) carried forward from prior experiences with the retailer's physical store.

Although these endeavors have offered useful insights for multi-channel retailers, extant studies have overlooked the argument that multiple reference points may be used for evaluating extensions (Dacin and Smith 1994; Loken and Ward 1990; Mao and Krishnan 2006). That is, in addition to comparisons drawn to the multi-channel retailer's physical store, perceived congruence with categoryspecific prototypical online stores (i.e., online stores that are construed as ideal or exemplar stores) could also influence purchase intentions in online stores of multichannel retailers. For example, while multi-channel retailers such as Barnes \& Noble, Best Buy, and JC Penney must pay attention to consumers' perceptions and beliefs pertaining to their online stores as well as evaluative comparisons made across their retail store formats, purchase intentions in their online stores are also likely to be influenced by customers' experiences with other representative or benchmark online stores. Therefore, to better understand purchase intentions in online stores of multi-channel retailers, it is important to address the transference of attitudes and beliefs from the physical store and the perceived congruence between the multi-channel retailer's online store with the parent, physical store, as well as prototypical online stores.

Figure 1 represents the theoretical framework developed in this study. Drawing from established behavior intention formation theories and extant research, we first discuss transference effects, namely, the carried over effects of attitude and trust pertaining to the multi-channel retailer's physical store. Next, the roles of image congruence between the multi-channel retailer's online store and (1) the parent, physical store as well as (2) a prototypical online store are examined. Subsequently, the relationships between attitude, trust, and purchase intentions in online stores of multi-channel retailers are presented. Finally, cross-national differences are hypothesized.

Transference of attitude toward and trust in the multi-channel retailer's physical store

In the context of multi-channel retailers, it is especially important to consider the influence of shoppers' prevailing attitudes and trust beliefs that are formed from prior interactions with the physical store and carried over to the online store. However, although the literature on trust and attitude formation processes lends theoretical support to the transfer of trust and attitude between closely related objects, these issues have been under-researched in the multichannel retailing literature (Wang et al. 2009).

In the social psychology literature, research on evaluative conditioning (e.g., Walther 2002; Walther and Grigoriadis 2004) suggests that attitude transference can occur when mere contiguity exists between two objects. According to this stream of research, when a subjectively neutral object is repeatedly represented along with a subjectively liked or disliked object, a significant valence shift is observed in the formerly neutral object (Walther 2002). That is, simple spatial or temporal co-occurrences of unconditioned and conditioned stimuli lead to the transfer of preferences, affective attributes, and valence from the unconditioned to the conditioned stimuli. Recent work in this area further proposes that attitude formation through evaluative conditioning is independent of the awareness of any contingencies, dependent on contiguity rather than any statistical contingency, and persists over time even in the absence of the unconditioned stimuli (Walther and Grigoriadis 2004; Walther and Langer 2008). In a similar vein, several studies on trust beliefs indicate that trust transfers from a known target to a closely related formerly unknown target (e.g., Doney et al. 1998; Strub and Priest 1976). Perceptions of proximity or "entitativity," wherein two entities are perceived as united and belonging to a group, are instrumental in the transfer of trust from one entity to the other (Campbell 1958; Stewart 2003). That is, when a new entity is encountered, it is assumed to be trustworthy when it demonstrates high entitativity with another trusted entity and subsequently acquires the definition of being trustworthy (Stewart 2003).

Many multi-channel retailers leverage associations across their store formats by utilizing common store-related cues and stimuli. In addition, multiple direct references to their online 
Fig. 1 The hypothesized framework of purchase intentions in online stores of multi-channel retailers

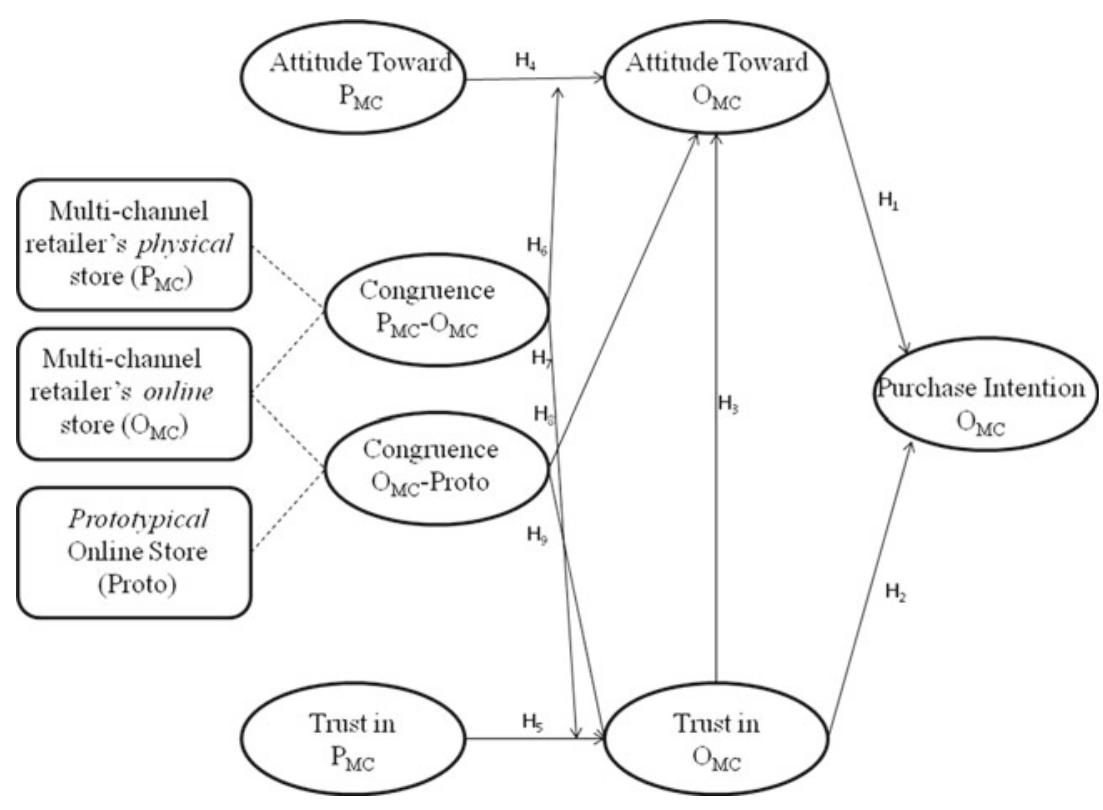

Note: $\mathrm{O}_{\mathrm{MC}}$ : Online store of multi-channel retailers; $\mathrm{P}_{\mathrm{MC}}$ : Physical store of multi-channel retailers; Proto: Prototypical online store stores are provided within the physical store environment, and vice versa. The presence of such associative cues, as well as shoppers' prior experiences with and impressions of a multichannel retailer's physical store, may play a critical role in influencing trust in and attitudes toward the online store. Specifically, Wang et al. (2009) recently found that prevailing attitudes toward a multi-channel retailer's physical store play a significant role in the formation of attitude toward the retailer's online store. Likewise, Stewart (2003) reports that when online stores of multi-channel retailers signal association with trusted physical stores, trusting beliefs regarding the online store will be greater than when associations are absent. Therefore:

H1: Shopper attitude toward the physical store of a multichannel retailer is positively related to attitude toward the online store.

$\mathrm{H} 2$ : Shopper trust in a multi-channel retailer's physical store is positively related to trust in the online store.

Image congruence between the multi-channel retailer's physical and online stores

Extant research indicates that, in addition to judgments of association between a multi-channel retailer's stores, a more complex evaluative process may be instrumental in influencing attitudes toward and trust in the multi-channel retailer's online store. Specifically, in the retailing literature, it is widely held that a retailer's image influences consum- ers' behavioral intentions, store patronage, and loyalty (e.g., Grewal et al. 1998; Sirgy and Samli 1985). Therefore, developing and communicating an attractive and consistent store image is essential for retailers to succeed ( $\mathrm{Hu}$ and Jasper 2007). Mazursky and Jacoby (1986, p. 147) define store image as: "(1) a cognition and/or affect (or a set of cognitions and/or affects) (2) which is (are) inferred (3) either from a set of ongoing perceptions and/or memory inputs attaching to a phenomenon (i.e. either an object or event such as a store, a product, a 'sale', etc.) (4) and which represent(s) what that phenomenon signifies to an individual." That is, store image is composed of cognitive and affective subjective judgments based on evaluations of the store's functional and psychological attributes that are salient to customers (Hu and Jasper 2007).

In the context of multi-channel retailing, several studies have drawn analogies between traditional retailers' migration to the online environment and brand extensions (e.g., Kwon and Lennon 2009a, b). Analogous to brands, a retailer's name is an information-laden cue that triggers retrieval of consumers' store perceptions, which in turn constitute store image (Grewal et al. 1998; Mazursky and Jacoby 1986). As extensions of stores are prevalent within and across retail formats (e.g., Gap vs. Baby Gap and Target vs. Target.com), research on brand extensions provides a suitable foundation for understanding the importance of store image perceptions across retail channels. With brand extensions, perception of congruence or the perceived degree of match or mismatch between parent brands and their extensions influences 
consumers' acceptance of the extension (e.g., Aaker and Keller 1990; Mao and Krishnan 2006; Ng and Houston 2006). Correspondingly, perceived congruence in the consumer held images of a multi-channel retailer's physical and online stores is expected to influence evaluation of a multichannel retailer's online store (Kwon and Lennon 2009a, b; Rafiq and Fulford 2005; Wang et al. 2009). When retailers expand to the online environment, transferring their core image to consumers' interaction experiences in the new environment is crucial for the success of the extension and the overall performance of the retailer (Teltzrow et al. 2007). Although some store-related associations may not be transferable to the online environment, the embeddedness of salient store associations in online interaction experiences becomes critical for image formation (Page and LepkowskaWhite 2002; Teltzrow et al. 2007). For example, images such as a store being upscale, fun, trendy, functional, serviceoriented, ego-sensitive, and value-driven, among others, are reflected in both physical and online stores of multi-channel retailers.

Schema theory supports that to the extent to which salient and relevant store associations are replicated, image congruence ensues and impacts consumers' attitude toward and beliefs regarding the online store. Schemas are the cognitive structures that are formed as a result of knowledge abstracted from prior exposure to an object and stored in memory (Fiske and Linville 1980). As they are representations of an object's attributes and the relationships between the attributes, they exert an influence on individuals' evaluations of unfamiliar entities in new or ambiguous contexts (Fiske and Pavelchak 1986). Schema theory suggests that information regarding a new entity is processed through comparison with established schemas and, subsequently, attitudes and beliefs are transferred from a schema to a new entity depending on the level of congruence (Goldstein and Chance 1980; Walton and Bower 1993). Therefore, as schema theory suggests that the existence of congruence facilitates greater attitudinal transfer between related entities (Fiske and Pavelchak 1986), congruence between the physical and online stores of a multi-channel retailer is expected to moderate attitude transference between the multi-channel retailer's physical and online stores. That is, attitude toward the physical store is likely to have a stronger impact on attitude toward the online store when high image congruence exists between the two stores. Likewise, studies on brand extensions indicate that, when a brand is extended, trust beliefs or expectations about the brand are transferred from the core brand to the extended brand as long as the extension is perceived to be similar or congruent with the core brand (Aaker and Keller 1990). In a recent study, Wang et al.
(2009) provide empirical support for the importance of image congruence in the context of multi-channel retailing and find that, when image congruence is high, consumers primarily draw from their pre-existing attitudes and beliefs about the retailer's physical store and demonstrate a schematic assessment of online store. Accordingly:

H3: The greater the perceived image congruence between a multi-channel retailer's physical and online stores, the greater the attitude transference from the multichannel retailer's physical to online stores.

H4: The greater the perceived image congruence between a multi-channel retailer's physical and online stores, the greater the trust transference from the multichannel retailer's physical to online stores.

Image congruence between the multi-channel retailer's online store and a prototype

In addition to communicating image congruence between their physical and online stores, multi-channel retailers must pay attention to shoppers' unique expectations from the online environment while serving customers online. Traditional retailers were relatively late entrants to Internet retailing; the concept was pioneered by pure Internet players. The online stores that prevailed (e.g., Amazon.com) created online store prototypes or benchmarks for other retailers (both multi-channel and other pure Internet players) to measure up to. The modern online retail customer is accustomed to medium-specific attributes such as faster access times, information richness, greater download speed, user-friendly page layout, capability to compare products/prices, user reviews, purchase recommendations, and delivery options, among other factors. Over time, based on browsing and shopping experiences online, customers identify a prototypical online store that encompasses desired levels of salient attributes. Therefore, to be competitive, multi-channel retailers must make sure that their online stores possess requisite points of parity with prototypical online stores. As shoppers visit a multichannel retailer's online store, congruence with a prototypical online store may facilitate greater acceptance of the store in the online environment, minimize confusion, support categorization, and, ultimately, evoke favorable evaluation.

Research on categorization theory suggests that exemplars or prototypes allow individuals to group or organize objects into categories, making it easier for them to judge a new stimulus (Sujan 1985). As Sujan (1985, p. 31) explicates, "categorization's basic premise is that people 
naturally divide the world of objects around them into categories, enabling an efficient understanding and processing of the environment. According to the categorization approach, if a new stimulus can be categorized as an example of a previously defined category, then the affect associated with the category can be quickly retrieved and applied to the stimulus." Prototypical online stores possess a fuzzy set of category attributes that best represent the category. Therefore, extending categorization theory, when online stores of multi-channel retailers are congruent with prototypical online stores, categorization should be expedited. In other words, the better the congruence between the multi-channel retailer's online store and a prototypical online store in terms of layout or retail policies (e.g., navigability, payment terms, delivery norms, after-sales service), the more complete is the belief and affect transfer from the representative store. Extending prior research to address a void in the multi-channel retailing literature, we hypothesize:

H5: Perceived image congruence between a multi-channel retailer's online store and a prototypical online store is positively related to attitude toward the multichannel retailer's online store.

H6: Perceived image congruence between a multi-channel retailer's online store and a prototypical online store is positively related to trust in the multi-channel retailer's online store.

Attitude, trust, and purchase intentions in online stores of multi-channel retailers

The theory of reasoned action posits that a person's beliefs regarding the nature of anticipated outcomes influence the formation of attitudes, which are a person's favorable or unfavorable evaluations toward a specific behavior (Ajzen and Fishbein 1980). Extending the theory, several studies have demonstrated that purchase intentions in online stores are positively influenced by favorable attitudes toward the online store (e.g., Evans et al. 1996; Shim et al. 2001) and trust in the store (e.g., Jarvenpaa and Tractinsky 1999; McKnight et al. 2002). Trust beliefs refer to the extent to which an individual believes that a target of trust will behave with benevolence, competence, honesty, and predictability in a given situation (McKnight et al. 2002). While positive attitudes indicate a favorable disposition toward the online store, trust mitigates risk and uncertainty associated with transactions in the online shopping environment. In addition to the direct influences of attitude and trust on purchase intentions, prior studies suggest that trust beliefs exert an indirect effect on purchase intentions by influencing attitude formation ( $\mathrm{Ha}$ and Stoel 2009;
Schlosser et al. 2006). These findings are in agreement with the theory of reasoned action, which proposes that the influence of beliefs on behavioral intentions is mediated by attitudes. Hence:

H7: Shopper attitude toward the online store of a multichannel retailer is positively related to purchase intentions.

H8: Shopper trust in the online store of a multi-channel retailer is positively related to purchase intentions.

H9: Shopper trust in the online store of a multi-channel retailer is positively related to attitude toward the online store.

Influence of thinking styles on congruence and transference effects

In the brand extension literature, studies have noted that attribute assessment and behavior based on congruence perceptions vary across cultures (e.g., Bottomley and Holden 2001). Therefore, an important contribution of this study is embedded in the cross-national comparison of the theoretical framework using data gathered from respondents from the U.S and S. Korea. The following similarities and differences prompted the decision to survey respondents from these two countries. First, analysts have noted that the two countries have comparable purchase patterns (Kwak et al. 2004), enjoy high Internet penetration rates, and have numerous multi-channel retailers (e.g., Walmart and walmart. com in the U.S. and Lotte and lotte.com in S. Korea). Specifically, a recent study indicates that $99 \%$ of S. Koreans with Internet access have shopped online compared to $94 \%$ in the U.S. (Nielsen/Nielsen Online 2008). In addition, the S. Korean Internet retail market is expected to grow to 16 billion dollars by 2010, and approximately seventy percent of S. Korean retailers have already become, or plan to become, multi-channel retailers (Choi and Park 2006). Second, studies have identified that consumers in the U.S. and S. Korea process product and brand information differently in the presence of contextual cues (Suri et al. 2004). Therefore, with the physical and online retail environments providing contextual settings, it is possible that multichannel retailers may be evaluated differently across these contexts by consumers in the U.S. and S. Korea. Third, although consumers in both nations place high importance on product quality, brand-based differences exist as respondents from S. Korea value brand loyalty more than those from U.S. who, in turn, value brand awareness/associations more than S. Koreans (Yoo and Donthu 2002). Finally, given the traditional cultural differences between Western and Eastern countries, a cross-national examination involving the U.S. and S. Korea could test the robustness of the framework in similar economic, yet different cultural, conditions (Hofstede 1997; Kwak et al. 2004; Nisbett et al. 2001). In summary, a 
cross-national study involving respondents from countries like the U.S. and S. Korea could, ultimately, guide multichannel retailers in understanding shopper perceptions in online retail environments and in formulating and managing global retail strategy.

Research on cross-national differences in thinking styles suggests that East Asian societies (e.g., S. Korea) are characterized by holistic thinking styles while Western societies (e.g., the U.S.) are characterized by analytic thinking styles (Nisbett et al. 2001). Nisbett et al. (2001, p. 293) define holistic thinking as "involving an orientation to the context or field as a whole, including attention to relationships between a focal object and the field, and a preference for explaining and predicting events on the basis of such relationships." In contrast, analytic thinking "involves a detachment of the object from its context, a tendency to focus on attributes of the object to assign it to categories, and a preference for using rules about the categories to explain and predict the object's behavior" (Nisbett et al. 2001, p. 293). This difference in thinking styles is often amplified due to social differences across cultures. Individuals in East Asian societies are part of several significant relationships and tend to be sensitive to both relationships between objects and changes in social contexts, whereas individuals in Western societies believe in discreteness and tend to evaluate objects using categoryspecific rules and properties (Monga and John 2007). That is, holistic thinkers draw inferences based on the relationships between objects as well as the relationship between objects and the field, whereas analytic thinkers draw inferences based on attribute and category evaluations (Masuda and Nisbett 2001).

Several studies offer support for the prevalence of distinctions in thinking styles across individuals from Eastern and Western societies (Nisbett et al. 2001). For instance, in a study by Chiu (1972), Chinese and American respondents were shown pictures of a man, a woman, and a child and were subsequently asked to group two together. The Chinese respondents were more likely to group the woman and child together, as the "mother takes care of the baby." The American respondents were more likely to group the man and woman together, as "they are both adults." Likewise, in a study where subjects were instructed to justify their grouping of objects, East Asians were more likely to justify the grouping of objects on the basis of relationships, whereas Westerners were more likely to justify the grouping of objects due to the prevalence of category-specific attributes (Ji and Nisbett 2001). Several other studies offer evidence that suggests that holistic thinkers use (1) relationships, rather than categories, for grouping and for judgments of associations and (2) family resemblance, rather than contextual rules, for judgments of similarity between objects (Masuda and Nisbett 2001; Nisbett et al. 2001). In fact, studies have specifically found that, compared to analytic thinkers, holistic thinkers make less use of categories for inductive inferences (Choi et al. 1997) and respond slower in exemplar-based categorization tasks (Norenzayan et al. 2000). In the brand extensions literature, Monga and John (2007) find that holistic and analytic thinking styles influence the evaluation of brand extensions and that holistic thinkers (1) perceive greater brand extension fit and (2) evaluate brand extensions more favorably than do analytic thinkers. They reason that holistic thinkers make judgments based on the affective or reputational relationships between the parent brand and the extension, as well as the other relationships such as the complementarity of the extension to the parent brand's product line, among others. In contrast, analytic thinkers are likely to make judgments of the extension based on evaluation of product class similarity and category attributes.

In the context of multi-channel retailers, this stream of research indicates that the proposed framework may work differently across holistic and analytic thinkers. For instance, holistic thinkers may define Best Buy as an electronics retailer, focus on the relationship between Best Buy and bestbuy.com, expect congruence between the two stores, and form preferences by transferring their feeling about Best Buy (the land-based store) toward bestbuy.com (the online store). In contrast, analytic thinkers may discretely classify Best Buy as a landbased electronics retailer and bestbuy.com as an online store, evaluate bestbuy.com based on its attributes as an online store, and form preference based on whether bestbuy.com possesses salient attributes that make the store attractive in the online retail environment. Since holistic thinkers are more likely to make inferences and judgments based on assessments of relationships between the multi-channel retailer's physical and online store, the effects of attitude transference and trust transference are expected to be greater for holistic thinkers than analytic thinkers. Similarly, the moderating effect of image congruence between the multi-channel retailer's physical and online store is also expected to be greater for holistic thinkers than analytic thinkers. However, analytic thinkers are expected to consider the image congruence between the multi-channel retailer's online store and a prototypical online store as they evaluate the prevalence of category-specific attributes. Therefore, the influence of congruence between a multi-channel retailer's online store and a prototypical online store on (1) attitude toward and (2) trust in the multi-channel retailer's online store is expected to be greater for analytic thinkers than holistic thinkers. To provide a more complete test of the 
proposed framework, we also examine how differences in thinking styles influence the relationships between trust in, attitude toward, and purchase intentions in online stores of multi-channel retailers. However, the literature on thinking styles, while implying that attitudes and trust may be formed differently across cultures, does not explicitly suggest that intra-relationships among these three constructs would differ. Therefore, as such, we do not present hypotheses on how differences in thinking styles would affect these relationships. Hence:

H10: (a) Attitude transference and (b) trust transference effects are greater for holistic thinkers than for analytic thinkers.

H11: The influence of image congruence between a multichannel retailer's physical and online stores on (a) attitude transference and (b) trust transference is greater for holistic thinkers than for analytic thinkers.

H12: The influence of image congruence between a multichannel retailer's online store and a prototypical online store on (a) attitude toward and (b) trust in the multi-channel retailer's online store will be greater for analytic thinkers than holistic thinkers.

\section{Control variables}

Several past studies on demographics and the Internet indicate that age, gender, and income are correlated with the use of the Internet and purchase intentions in online stores (e.g., Schlosser et al. 2006). Researchers have also indicated that trust toward the Internet as a shopping medium and channel should be included in studies on purchase intention in specific online stores. Further, while we apply the theory of reasoned action to specify a hypothesis on the relationship between trust in and attitude toward the multi-channel retailer's online store, we also acknowledge that a similar relationship could also apply to the physical store. To provide a more robust test of our framework, we control for (1) the influence of three demographic variables (age, gender, and income), (2) the relationship between channel trust and purchase intentions, and (3) the relationship between trust in and attitude toward the multi-channel retailer's physical store.

\section{Method}

As discussed earlier, the study used respondents from the U.S. and S. Korea. A questionnaire was developed by adapting existing measures from studies on thinking tendencies (Choi et al. 2007; Nisbett et al. 2001), image congruence (Ahluwalia and Gurhan-Canli 2000; John et al.
1998), and online attitudes, trust, and behavior (Jarnvepaa and Tractinsky 1999; McKnight et al. 2002). The instrument was pre-tested, translated, and back-translated before administration. Subjects from a large southwestern U.S. university and a large $\mathrm{S}$. Korean university were selected to participate in the study. After screening the respondents to make sure they had shopping experience in both store formats of multi-channel retailers, respondents were instructed to specify a multi-channel retailer they were most familiar with and complete the survey with respect to that retailer. All of the multi-channel retailers that respondents chose were land-based retailers who transitioned into multi-channel retailers by establishing online stores. From a pool of 565 young adults, 533 completed the questionnaire, 185 from the U.S. and 318 from S. Korea. The majority of respondents were male $(57.3 \%$ for the U.S. and $51.5 \%$ for S. Korea), between 18 and 25 years old (91.2\% for the U.S. and $72.9 \%$ for S. Korea), and with a household income equivalent to $\$ 60,000$ or less $(75.4 \%$ for the U.S. and $52.5 \%$ for S. Korea).

\section{Preliminary analysis}

The holistic thinking tendency difference between the U.S. and S. Korea was assessed through an analysis of covariance (ANCOVA), using SPSS 14.0, while controlling for age, gender, and household income (factor-covariance interaction was not significant $(\mathrm{F}(2,497)=.938, p=.392))$. As expected, the analysis suggests a difference on thinking tendencies between the U.S. and S. Korea $(\mathrm{F}(1,499)=$ $39.803, p<.001$ ), with respondents from $\mathrm{S}$. Korea (mean= 5.068/5.226) scoring higher on holistic thinking than those from the U.S. (mean=4.601/4.814). None of the three demographic covariates were significant.

The indicators' internal and external consistencies were assessed using confirmatory factor analysis using LISREL 8.72 (Anderson and Gerbing 1988). The fit indices $\left(\chi^{2}=874.03, \chi^{2} / \mathrm{df}=1.95 ;\right.$ RMSEA $=0.059$, $\mathrm{SRMR}=0.039 ; \mathrm{GFI}=0.92 ; \mathrm{CFI}=0.97 ; \mathrm{NNFI}=0.96$ ) are within acceptable ranges and the factor loadings are statistically significant $(p<.01 ; \mathrm{t}$-values ranging from 9.24 to 30.28 ), suggesting an adequate model fit and unidimensionality. The composite reliabilities range from .74 to .96 (see Appendix Table 5). Across datasets from the U.S. and S. Korea, the average variance extracted (AVE) for all constructs is within acceptable ranges $(>.50)$ and substantially higher than the squared correlation between the constructs and all other constructs (see Appendix Table 5) suggesting adequate unidimensionality, discriminant validity, and composite reliability (Bagozzi and Yi 1988; Fornell and Larcker 1981). Common method variance (CMV) was (1) paid attention to during the study design process following recommendations in the extant 
literature (e.g., Churchill and Peter 1984; Podsakoff et al. 2003; Lindell and Whitney 2001) and (2) analyzed using Harman's one-factor test (Podsakoff et al. 1984; Podsakoff and Organ 1986) and suggestions provided by Lindell and Whitney (2001). The results indicate that it is unlikely that CMV has significantly inflated or deflated the results. A summary of all the measures used in the study is presented in Appendix Table 6.

Moderation or interaction effect was tested using the procedure that Ping (1995) developed based on recommendations from past researchers (Anderson and Gerbing 1988; Kenny and Judd 1984). In Ping's (1995) approach, the interaction of two latent variables (e.g., $\mathrm{X}$ and $\mathrm{Z}$ ) can be represented by the multiplication of the sum of each construct's observed variables (e.g., $\left(\mathrm{x}_{1}+\mathrm{x}_{2}+\ldots\right)\left(\mathrm{z}_{1}+\mathrm{z}_{2}+\right.$ ... )). To avoid interpretational confounding, this should be done after making sure each observed variable has been centered and only if each latent variable is unidimensional (see Ping 1995). The model testing for moderation includes the main effects of each latent variable and a multiplicative variable for the interaction effect. The loading and errors for the latent variables (e.g., $\mathrm{X}$ and $\mathrm{Z}$ ) and the interaction variable are determined from unstandardized loadings (Ping 1995). The errors for the latent variables are as follows (Ping 1995, p. 338):

$$
\begin{aligned}
\lambda_{\mathrm{xz}}= & \left(\lambda_{x 1}+\lambda_{x 2}\right)\left(\lambda_{\mathrm{z} 1}+\lambda_{\mathrm{z} 2}\right) \\
\theta_{\varepsilon \mathrm{xz}}= & \left(\lambda_{\mathrm{x} 1}+\lambda_{\mathrm{x} 2}\right)^{2} \operatorname{VarX}\left(\theta_{\varepsilon \mathrm{x} 1}+\theta_{\varepsilon \mathrm{x} 2}\right) \\
& +\left(\lambda_{\mathrm{z} 1}+\lambda_{\mathrm{z} 2}\right)^{2} \operatorname{VarZ}\left(\theta_{\varepsilon z 1}+\theta_{\varepsilon z 2}\right) \\
& +\left(\theta_{\varepsilon \mathrm{x} 1}+\theta_{\varepsilon \mathrm{x} 2}\right)\left(\theta_{\varepsilon z 1}+\theta_{\varepsilon z 2}\right)
\end{aligned}
$$

The values for both equations are obtained by first running the proposed model without the interaction variable followed subsequently by a model with the proposed interaction (for further information on this approach, see Cortina et al. (2001) and Ping (1995)). Therefore, using LISREL 8.72, a model excluding the proposed interactions was run for both groups (U.S. and S. Korea) simultaneously as required in a structural equations modeling (SEM) multiple-group analysis procedure (Bollen 1989; Byrne 1998) (multiple-group analysis procedures are elaborated on in the following section). The model fit indices were adequate $\left(\chi^{2}=935.28 ; \chi^{2} / \mathrm{df}_{470}=1.99\right.$ RMSEA $=0.06$, SRMR $=0.056$; GFI $=0.92)$ suggesting that the values can be used to calculate the loading and error of the proposed interactions. After computing the values for the loading and error using Ping's (1995) equations, the hypotheses were tested.

Hypothesis testing

Using LISREL 8.72, a multiple-group structural equation modeling (SEM) analysis was employed to test the hypotheses (e.g., Bollen 1989; Byrne 1998; Hancock and Mueller 2006). Multiple-Group SEM, a multivariate simultaneous test of pair-wise relationships across groups, reduces the probability of Type I error (Singh 1995). In addition, SEM analysis is an appropriate test of mediation and moderation effects that reduces the risk of false negative and conditional findings that may occur with techniques like ANOVA (e.g., Kenny and Judd 1984; Ping 1995). A series of runs were used to assess the influence of differences in thinking styles among respondents from the U.S. and S. Korea.

In the first run, a model (Model 1) with all structural parameters constrained equally across the two groups, without the control variables, is tested. This run permits the assessment of all the hypotheses except for hypotheses H10-H12, which focus on inter-group differences. In the second run, a model (Model 2) with the structural parameters unconstrained across the two groups is tested to examine whether there are differences between the two groups (U.S. and S. Korea). The chi-square for Model 1 (constrained) will naturally be higher than that of Model 2 (unconstrained) since Model 1 is nested in Model 2. Also, if the difference in chi-squares between Model 1 and Model 2 is significant, it suggests that there are differences across some or all the parameters, which subsequently need to be tested individually. In this case, the models' fit indices are adequate (see Table 1). Analysis of the chisquare indicates that Model 2 provides a significant improvement over Model $1(p<.05$ for the chi-square difference of $22.18_{\mathrm{df}=11}$; two out of the 13 model paths are used as control variables and they are not part of the test between the constrained and unconstrained models) and that there are differences in the model's parameters across the two groups.

Next, the parameter differences are tested through a chisquare difference test between the constrained model (Model 1) and a model with each path tested unconstrained (Model 2 ). In this case, the parameter to be tested is made unconstrained in Model 1 (constrained), increasing the degrees of freedom by one for Model 2 (unconstrained). With one parameter unconstrained, the chi-square of Model 1 is higher than the chi-square of Model 2. If the difference in chi-squares is significant $\left(\Delta \chi_{/ \mathrm{df}=1}{ }^{2}>3.84\right)$, it indicates a difference between the two groups for the parameter tested. The difference in unstandardized values for that parameter between the two groups indicates the group in which the parameter exerts a greater influence (see Table 2 for $\Delta \chi^{2}$ and Model 2 values) (Byrne 1998; Hancock and Mueller 2006).

\section{Results}

Initial findings and post-hoc analysis

Prior researchers have posited that image congruence between the physical and online stores of multi-channel 
Table 1 Goodness of fit-indices for Model 1 (constrained) and Model 2 (unconstrained)

\begin{tabular}{|c|c|c|c|c|c|c|}
\hline Model & Specifications & $\chi^{2}(\mathrm{df})$ & $\chi^{2} / \mathrm{df}$ & GFI/CFI & RMSEA & SRMR \\
\hline Model 1 & Constrained & $1,191.01(558)$ & 2.13 & $.90 / .96$ & .065 & .064 \\
\hline Model 2 & Unconstrained & $1,168.88(547)$ & 2.14 & $.90 / .96$ & .065 & .057 \\
\hline Model 2 (excluding Trust $\left(\mathrm{P}_{\mathrm{MC}}\right)$ x Congruence $\left(\mathrm{P}_{\mathrm{MC}}-\mathrm{O}_{\mathrm{MC}}\right)$ & Unconstrained & $1052.90(508)$ & 2.07 & $.91 / .97$ & .063 & .055 \\
\hline Model 2 (excluding Attitude $\left(\mathrm{P}_{\mathrm{MC}}\right)$ x Congruence $\left(\mathrm{P}_{\mathrm{MC}}-\mathrm{O}_{\mathrm{MC}}\right)$ & Unconstrained & $996.19(508)$ & 1.96 & $.91 / .97$ & .060 & .052 \\
\hline Model 1b & Constrained & $960.24(479)$ & 2.00 & $.91 / .97$ & .061 & .066 \\
\hline Model 2b & Unconstrained & $935.28(470)$ & 1.98 & $.92 / .97$ & .060 & .056 \\
\hline
\end{tabular}

$\mathrm{P}_{\mathrm{MC}}$ refers to the physical store of multi-channel retailers, while $\mathrm{O}_{\mathrm{MC}}$ refers to the online store of multi-channel retailers

retailers moderates the transference of attitudes and trust from the physical store to the online store. Accordingly, to test the moderation effect, we included both interaction and direct effects in our analysis (Ping 1995). However, the results (see Table 1, Model 1) indicate that both of the proposed interaction effects involving congruence between the physical and online stores ( $\mathrm{H} 3$ and $\mathrm{H} 4)$ are not supported. But image congruence between the multichannel retailer's physical and online store does exert a direct effect on both trust in and attitude toward the multichannel retailer's online store. Therefore, in addition to the generation of findings pertaining to the proposed model, we

Table 2 Results of multiple group analysis

\begin{tabular}{|c|c|c|c|c|}
\hline Effects & $\begin{array}{l}\text { Model } 1 \\
\text { Equally Constrained } \\
\left.\text { Value (C.R. }{ }^{\mathrm{b}}\right)\end{array}$ & $\begin{array}{l}\text { Model } 2 \\
\text { U.S. } \\
\text { Value (C.R.' })\end{array}$ & $\begin{array}{l}\text { Model } 2 \\
\text { S. Korea } \\
\left.\text { Value (C.R. }{ }^{b}\right)\end{array}$ & $\begin{array}{l}\text { Cultural } \\
\text { Difference } \\
\chi^{2} \Delta^{a}\end{array}$ \\
\hline \multicolumn{5}{|l|}{ Direct Effects } \\
\hline H1: Attitude $\left(\mathrm{P}_{\mathrm{MC}}\right)$ on Attitude $\left(\mathrm{O}_{\mathrm{MC}}\right)$ & $.04(1.06)$ & $-.02(-.52)$ & $.13(2.07)^{*}$ & H10a:9.73** \\
\hline $\mathrm{H} 2$ : Trust $\left(\mathrm{P}_{\mathrm{MC}}\right)$ on Trust $\left(\mathrm{O}_{\mathrm{MC}}\right)$ & $.37(6.47)^{* * *}$ & $-.02(-.14)$ & $.40(6.69)^{* * *}$ & H10b:3.99* \\
\hline H3: Attitude $\left(\mathrm{P}_{\mathrm{MC}}\right) \times$ Congruence $\left(\mathrm{P}_{\mathrm{MC}}-\mathrm{O}_{\mathrm{MC}}\right)$ on Attitude $\left(\mathrm{O}_{\mathrm{MC}}\right)$ & $.05(1.76)$ & $.04(1.06)$ & $.03(.63)$ & H11a:1.60 \\
\hline H4: Trust $\left(\mathrm{P}_{\mathrm{MC}}\right) \mathrm{x}$ Congruence $\left(\mathrm{P}_{\mathrm{MC}}-\mathrm{O}_{\mathrm{MC}}\right)$ on Trust $\left(\mathrm{O}_{\mathrm{MC}}\right)$ & $.08(1.54)$ & $.08(.76)$ & $-.02(-.40)$ & H11b:9.29** \\
\hline H5: Congruence ( $\mathrm{O}_{\mathrm{MC}}-$ Proto) on Attitude $\left(\mathrm{O}_{\mathrm{MC}}\right)$ & $.12(3.32)^{* *}$ & $.11(2.53)^{*}$ & $.12(2.19)^{*}$ & H12a: 1.96 \\
\hline H6: Congruence $\left(\mathrm{O}_{\mathrm{MC}}\right.$-Proto $)$ on Trust $\left(\mathrm{O}_{\mathrm{MC}}\right)$ & $.07(1.81)$ & $.15(2.16)^{*}$ & $.03(.66)$ & H12b: .79 \\
\hline H7: Attitude $\left(\mathrm{O}_{\mathrm{MC}}\right)$ on Purchase Intentions & $.54(7.54)^{* * *}$ & $.55(3.45)^{* *}$ & $.55(6.73)^{* * *}$ & 0.94 \\
\hline H8: Trust $\left(\mathrm{O}_{\mathrm{MC}}\right)$ on Purchase Intentions & $.33(5.39)^{* * *}$ & $.24(2.44)^{*}$ & $.41(4.95)^{* * *}$ & $3.90 *$ \\
\hline H9: Trust $\left(\mathrm{O}_{\mathrm{MC}}\right)$ on Attitude $\left(\mathrm{O}_{\mathrm{MC}}\right)$ & $.29(6.23)^{* * *}$ & $.23(4.04)^{* *}$ & $.32(4.34)^{* * *}$ & $6.63 * * *$ \\
\hline Congruence $\left(\mathrm{P}_{\mathrm{MC}}-\mathrm{O}_{\mathrm{MC}}\right)$ on Attitude $\left(\mathrm{O}_{\mathrm{MC}}\right)$ & $.21(4.98)^{* * *}$ & $.20(3.75)^{* *}$ & $.22(3.26)^{* *}$ & $6.82 * *$ \\
\hline Congruence $\left(\mathrm{P}_{\mathrm{MC}}-\mathrm{O}_{\mathrm{MC}}\right)$ on Trust $\left(\mathrm{O}_{\mathrm{MC}}\right)$ & $.31(7.06)^{* * *}$ & $.41(5.17)^{* *}$ & $.33(5.90)^{* * *}$ & -0.01 \\
\hline Trust $\left(\mathrm{P}_{\mathrm{MC}}\right)$ on Attitude $\left(\mathrm{P}_{\mathrm{MC}}\right)$ (control) & $.97 / .64(8.17 / 11.62)^{* * *}$ & $.92(8.25)^{* * *}$ & $.64(11.60)^{* * *}$ & NA \\
\hline Channel Trust on Purchase Intentions (control) & $.10 / .11(1.72 / 1.61)$ & $.13(2.18)^{*}$ & $.08(1.15)$ & NA \\
\hline \multicolumn{5}{|l|}{ Total Effects on Purchase Intentions } \\
\hline Trust $\left(\mathrm{P}_{\mathrm{MC}}\right)$ & $.19(5.34)^{* * *}$ & $-.02(-.33)$ & $.28(2.83)^{* *}$ & \\
\hline Attitude $\left(\mathrm{P}_{\mathrm{MC}}\right)$ & $.02(1.05)$ & $-.01(-.52)$ & $.07(2.15)^{*}$ & \\
\hline Congruence $\left(\mathrm{P}_{\mathrm{MC}}-\mathrm{O}_{\mathrm{MC}}\right)$ & $.26(7.60)^{* * *}$ & $.26(5.07)^{* * *}$ & $.31(4.86)^{* * *}$ & \\
\hline Trust $\left(\mathrm{P}_{\mathrm{MC}}\right) \times$ Congruence $\left(\mathrm{P}_{\mathrm{MC}}-\mathrm{O}_{\mathrm{MC}}\right)$ & $.04(1.52)$ & $.03(.75)$ & $-.01(-.23)$ & \\
\hline Attitude $\left(\mathrm{P}_{\mathrm{MC}}\right) \times$ Congruence $\left(\mathrm{P}_{\mathrm{MC}^{-}}-\mathrm{O}_{\mathrm{MC}}\right)$ & $.03(1.72)$ & $.02(1.02)$ & $.02(.86)$ & \\
\hline Congruence $\left(\mathrm{O}_{\mathrm{MC}}\right.$-Proto $)$ & $.10(3.56)^{* *}$ & $.12(3.08)^{* *}$ & $.09(1.74)$ & \\
\hline Trust $\left(\mathrm{O}_{\mathrm{MC}}\right)$ & $.42(8.37)^{* * *}$ & $.37(4.47)^{* * *}$ & $.52(7.42)^{* * *}$ & \\
\hline Attitude $\left(\mathrm{O}_{\mathrm{MC}}\right)$ & $.54(7.54)^{* * *}$ & $.55(3.45)^{* *}$ & $.55(3.41)^{* *}$ & \\
\hline Channel Trust & $.10 / .11(1.72 / 1.96)$ & $.13(2.18)^{*}$ & $.08(1.44)$ & \\
\hline
\end{tabular}

$\mathrm{O}_{\mathrm{MC}}$ : Online store of multi-channel retailers; $\mathrm{P}_{\mathrm{MC}}$ : Physical store of multi-channel retailers; Proto: Prototypical online store.

${ }^{a}$ The chi square difference is the value difference between the constrained model (Model 1) and a model for which the indicated path can take on different values in each sub-sample (Model 2). ${ }^{\mathrm{b}}$ C.R. is the critical ratio ( $t$-value).

${ }^{*} p<.05 ; * * p<.01 ; * * * p<.001$ 
proceeded to test whether the exclusion of one or both of the interaction variables would be supported (see Fig. 2). When the chi-squared difference between the proposed model and revised model is significant, there is evidence that the parameters in question can be deleted from the model (e.g., Bagozzi and Yi 1988).

The proposed unconstrained model (Model 2) was used as the basis for comparison. Results (Table 2) indicate that excluding the interaction of image congruence between the multi-channel retailer's stores and the trust transference relationship significantly improves the model $\left(\Delta \chi_{/ \mathrm{df}=39}{ }^{2}=\right.$ $115.98 ; p<.001)$. Furthermore, results indicate that removing the interaction of image congruence between the multichannel retailer's stores and the attitude transference relationship also improves the model $\left(\Delta \chi_{/ \mathrm{df}=39}{ }^{2}=172.69 ; p<.001\right)$. Finally, a model excluding both interactions (Model 2b) was compared against the base model (Model 2). Results (see Table 2; $\Delta \chi_{/ \mathrm{df}=77^{2}}=233.6 ; p<.001$ ) indicate a significant model improvement and confirm the improvement of the model by deleting both interaction parameters. Therefore, Model $2 \mathrm{~b}$ is subsequently utilized for hypotheses testing and for examining differences between the two groups of respondents. Although the fit indices suggest that a model without the moderation paths is superior (Fig. 2), there were no observable differences in any of the other relationships when compared with the original model (Fig. 1).

Subsequently, transference effects, congruence effects, and differences in thinking styles were analyzed (see Table 3, Model 1b). As for transference effects, we tested for the transference of both attitude and trust from the physical to online stores of the multi-channel retailer. In this case, no transference effect was observed for the two attitude constructs thereby, failing to support H1. However, the results indicate the existence of a positive relationship between trust in the physical and online store, thereby supporting H2. Next, image congruence between (1) the multi-channel retailer's physical and online stores, as well as (2) the multi-channel retailer's online store and a prototypical online store were examined. Image congruence between the multi-channel retailer's physical and online store does exert a direct effect on both trust in and attitude toward the multi-channel retailer's online store. That is, although we did not find support for the moderating role of image congruence, as hypothesized in $\mathrm{H} 3$ and $\mathrm{H} 4$, the respecified model provides support for the direct effects on trust in and attitude toward the multi-channel retailer's online store. With regard to the image congruence between the multi-channel retailer's online store and a prototypical online store, we find a direct positive influence on attitude toward the multi-channel retailer's online store, but no significant influence on trust in the multi-channel retailer's online store. That is, while H5 is supported, H6 is not. This indicates that comparisons drawn with prototypes may be more important in influencing behavioral predispositions, while deeper processes may underlie the formation of trust. As for the relationships between trust, attitude, and purchase intentions with respect to the multi-channel retailer's online store, shoppers' attitude toward and trust in a multi-channel retailer's online store positively influence purchase intentions, thus supporting $\mathrm{H} 7$ and $\mathrm{H} 8$. Further, as hypothesized, trust in the online store positively influences attitude toward the online store, lending support

Fig. 2 The re-specified framework

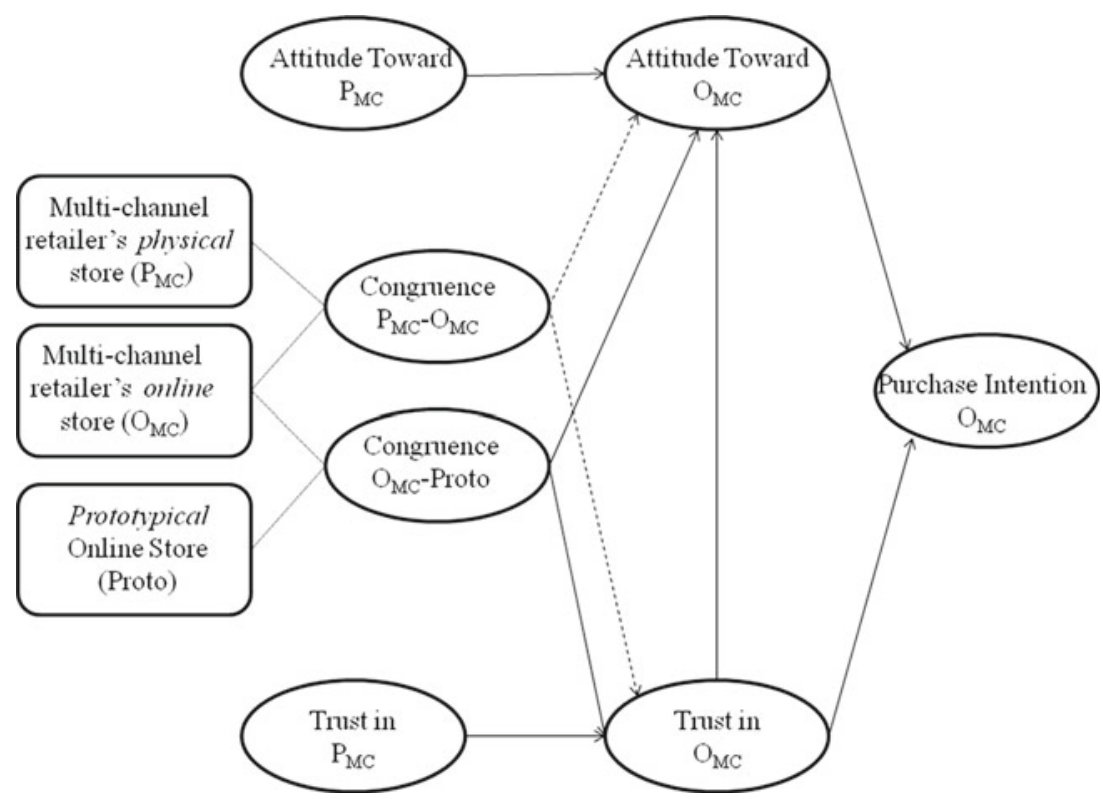

Note: $\mathrm{O}_{\mathrm{MC}}$ : Online store of multi-channel retailers; $\mathrm{P}_{\mathrm{MC}}$ : Physical store of multi-channel retailers; Proto: Prototypical online store 
Table 3 Results of multiple group analysis

\begin{tabular}{lllll}
\hline & Model 1b & Model 2b & Model 2b & Cultural Difference $\chi^{2} \Delta{ }^{a}$ \\
Effects & Equally Constrained & U.S. & S. Korea \\
& Value (C.R. ${ }^{b}$ & Value (C.R. $\left.{ }^{b}\right)$ & Value (C.R. $^{b}$ )
\end{tabular}

\begin{tabular}{|c|c|c|c|}
\hline $.01(0.29)$ & $-.05(-1.12)$ & $.12(1.95)^{*}$ & H10a: $9.58^{* *}$ \\
\hline $.34(6.64)^{* * *}$ & $-.08(-0.70)$ & $.42(7.34)^{* * *}$ & H10b: $8.54 * *$ \\
\hline $.22(5.24)^{* * *}$ & $.21(3.81)^{* *}$ & $.22(3.53)^{* *}$ & $6.58 * \mathrm{~d}$ \\
\hline $.32(7.40)^{* * *}$ & $.43(5.31)^{* *}$ & $.30(5.90)^{* * *}$ & $-.14^{\mathrm{d}}$ \\
\hline $.11(3.20)^{* *}$ & $.11(2.47)^{*}$ & $.12(2.20)^{*}$ & H12a: 1.98 \\
\hline $.07(1.85)$ & $.15(2.21)^{*}$ & $.04(0.87)$ & H12b: -.03 \\
\hline $.54(7.46)^{* * *}$ & $.55(3.41)^{* *}$ & $.55(6.70)^{* * *}$ & $4.20^{*}$ \\
\hline $.33(5.43)^{* * *}$ & $.24(2.47)^{*}$ & $.41(4.94)^{* * *}$ & $2.53^{*}$ \\
\hline $.29(6.39)^{* * *}$ & $.24(4.12)^{* *}$ & $.33(4.45)^{* * *}$ & $6.84 * *$ \\
\hline $.92 / .63(8.17 / 11.48)^{* * *}$ & $.88(8.20)^{* * *}$ & $.64(11.51)^{* * *}$ & NA \\
\hline $.10 / .11(1.70 / 1.58)$ & $.12(2.16)^{*}$ & $.08(1.12)$ & NA \\
\hline $.17(5.15)^{* * *}$ & $-.06(-1.12)$ & $.29(3.62)^{* *}$ & \\
\hline $.01(0.29)$ & $-.03(-1.07)$ & $.07(2.09)^{*}$ & \\
\hline $.27(7.85)^{* * *}$ & $.27(5.12)^{* * *}$ & $.30(4.59)^{* * *}$ & \\
\hline $.10(3.50)^{* *}$ & $.11(3.08)^{* *}$ & $.09(1.88)$ & \\
\hline $.49(8.48)^{* * *}$ & $.37(4.52)^{* * *}$ & $.59(7.42)^{* * *}$ & \\
\hline $.54(7.46)^{* * *}$ & $.55(3.41)^{* *}$ & $.55(3.41)^{* *}$ & \\
\hline $.10 / .11(1.70 / 1.93)$ & $.12(2.16)^{*}$ & $.08(1.42)$ & \\
\hline
\end{tabular}

${ }^{\mathrm{a}}$ The chi square difference is the value difference between the constrained model (Model 1b) and a model for which the indicated path can take on different values in each sub-sample (Model $2 b$ ).

${ }^{\mathrm{b}}$ C.R. is the critical ratio ( $t$-value).

${ }^{\mathrm{c}} \mathrm{As} \mathrm{H} 3$ and $\mathrm{H} 4$ were not supported, the direct influence of the two congruence variables on attitude toward and trust in the multi-channel retailer's online store were tested in the revised model.

${ }^{\mathrm{d}}$ As $\mathrm{H} 11$ (a,b) were not supported, cultural differences pertaining to the direct influence of the image congruence between a multi-channel retailer's physical and online store were tested in the revised model.

${ }^{*} p<.05 * * p<.01 * * * p<.001$

to hypothesis H9. These results are in correspondence with the extensive body of knowledge integrating the theory of reasoned action and online shopping behavior. Overall, the above analysis points toward the existence of transference and congruence effects. That is, the results show that, for multi-channel retailers, shoppers' trust beliefs are carried over from the physical store to the online store and indirectly influence purchase intentions. Likewise, congruence between the multi-channel retailer's physical and online stores plays a pivotal role by influencing trust in and attitude toward the online store and, ultimately, purchase intentions. Finally, congruence between the multi-channel retailer's online store and a prototypical online store contributes toward purchase intentions by influencing attitude toward the multi-channel retailer's online store.

Next, all proposed relationships were examined across respondents from cultures with analytic (U.S.) and holistic
(S. Korea) thinking styles. Corresponding results for the significant differences across the two groups of respondents are also presented in Table 3. Overall, the results indicate significant differences for the following relationships: (1) attitude transference, (2) trust transference, (3) image congruence between the multi-channel retailer's physical and online stores and attitude toward the online store, (4) attitude toward the multi-channel retailer's online store and purchase intentions, (5) trust in the multi-channel retailer's online store and purchase intentions, and (6) trust in and attitude toward the multi-channel retailer's online store. Appropriate differences in chi-squares are provided in Table 3. Specifically, as hypothesized in H10 (a,b), attitude transference and trust transference were greater for holistic thinkers than analytic thinkers. As the moderating influence of image congruence between the physical and online stores of a multi-channel retailer was not supported, the cultural differences hypothesized in $\mathrm{H} 11$ (a,b) were not verified. 
However, in the re-specified model, the direct impact of congruence between the physical and online stores of a multi-channel retailer on attitude toward the online store was greater for holistic thinkers. In contrast, the impact of congruence between the physical and online stores of a multi-channel retailer on trust in the online store shows no statistical difference although the effects are significant in both groups. With regard to the impact of congruence between a multi-channel retailer's online store and a prototypical online store on attitude toward the multichannel retailer's online store, we expected the results to be greater in analytic thinkers than in holistic thinkers. However, while the effects were significant for both groups, they were not statistically significant across the groups. As for the impact of congruence between a multi-channel retailer's online store and prototypical online store on trust in the multi-channel retailer's online store, the effect was significant only among analytic thinkers. That is, we do not find support for H12 (a,b). Finally, although not hypothesized, we examined any cultural differences in the relationships between attitude, trust, and purchase intentions with regard to a multi-channel retailer's online store. We find that the relationships between trust and attitude, trust and purchase intentions, and attitude and purchase intentions are greater for holistic thinkers than for analytic thinkers. A summary of all the proposed hypotheses and their corresponding significances is provided in Table 4. In the following section, we discuss the findings, the implications for multi-channel retail strategy, suggestions for future research, and potential limitations of the study.

\section{Discussion and conclusions}

The focus of this study was on traditional retailers who have transformed into multi-channel retailers through the creation of their own online stores. Despite the prevalence of research on online shopping behavior, very few studies have focused on online stores of multi-channel retailers. As these stores are likely to be influenced by shoppers' attitudes and trust beliefs that are carried over from the multi-channel retailer's physical stores, as well as comparisons drawn to the images of the physical store and prototypical online stores, we examine transference and congruence effects on trust, attitude, and purchase intentions. Further, highlighting the fact that several retailers now operate as multi-channel retailers in different countries, we evaluate the influence of cultural differences in thought processes on shoppers' evaluation of online stores of multichannel retailers. In recent years, global retailing powerhouses (e.g., Carrefour, Tesco, and Walmart) have struggled in Asian retail markets (e.g., China, Japan, and S. Korea). Hence, we believe that an understanding of cultural differences in information processing styles will be relevant for retailers' performance. Specifically, complementing and extending work on differences in thinking styles, we test our theoretical framework in cultures with analytic (U.S.) and holistic (S. Korea) thinking styles. Overall, we find support for our theses that transference effects and congruence effects impact shoppers' purchase intentions in online stores of multichannel retailers. In addition, when the framework is tested across cultures, we find several interesting findings that have specific implications for multi-channel retailers and suggest possibilities for future research.

In the overall (equally constrained across the two groups) model, we find support for trust transference although not for attitude transference. Further, image congruence between the multi-channel retailer's physical and online stores exerts a positive influence on both attitude toward and trust in the multi-channel retailer's online store. However, congruence between the multi-channel retailer's online store and a prototypical online store exerts a positive influence on attitude toward the multi-channel retailer's online store and not on trust in the store. Finally, interrelationships were observed between trust in and attitude toward the multi-channel retailer's online store, as well as between each construct and purchase intentions. Based on the above, it is clear that multi-channel retailers have to enhance trust beliefs and shopper attitudes as they attempt to increase purchase intentions in their online stores. Toward this end, this study offers two major implications. First, multi-channel retailers must manage shoppers' trust in their online stores by paying attention to trust beliefs that are carried over from their physical store, as well as maintaining image congruence between the physical and online stores. Therefore, to facilitate the formation of trust in their online stores, multi-channel retailers must develop strategies to augment trust in their physical store, signal associations between the two stores, and maintain similarities in salient store attributes across retail formats to maintain image congruence. Second, multichannel retailers must manage shopper attitudes toward their online stores by paying attention to not only trust beliefs but also the effects of image congruence between the physical and online stores and image congruence between the online store and prototypical online stores. This implies that attitude formation is a complex phenomenon that is influenced by comparisons drawn across the multi-channel retail formats, as well as the evaluation of attributes that are deemed essential in the online retail environment. Collectively, these results suggest that purchase intention in online stores of multi-channel retailers is contingent upon both transference and congruence effects.

With respect to the influence of differences in thinking styles, we find that the transference of trust and attitude occurs only among holistic thinkers and not among analytic 
Table 4 Summary of findings

\begin{tabular}{|c|c|}
\hline Hypotheses and Effects Tested & Findings \\
\hline H1: Attitude transference from physical store to online store. & Not supported \\
\hline $\mathrm{H} 2$ : Trust transference from physical store to online store. & Supported $(p<.001)$ \\
\hline H3: Interaction effect of congruence $\left(\mathrm{P}_{\mathrm{MC}}-\mathrm{O}_{\mathrm{MC}}\right)$ on attitude transference & Not supported. \\
\hline $\mathrm{H} 4$ : Interaction effect of congruence $\left(\mathrm{P}_{\mathrm{MC}}-\mathrm{O}_{\mathrm{MC}}\right)$ on trust transference. & Not supported. \\
\hline H5: Effect of congruence ( $\mathrm{O}_{\mathrm{MC}}$-Proto) on attitude toward online store. & Supported $(p<.01)$ \\
\hline H6: Effect of congruence ( $\mathrm{O}_{\mathrm{MC}}$-Proto) on trust in online store. & Not supported. \\
\hline H7: Effect of attitude toward online store on purchase intentions. & Supported $(p<.001)$ \\
\hline H8: Effect of trust toward online store on purchase intentions. & Supported $(p<.001)$ \\
\hline H9: Effect of trust toward online store on attitude toward online store. & Supported $(p<.001)$ \\
\hline H10a: Attitude transference is greater for holistic thinkers. & Supported $(p<.01)$ \\
\hline H10b: Trust transference is greater for holistic thinkers. & Supported $(p<.05)$ \\
\hline $\begin{array}{l}\text { H11a: The effect of congruence }\left(\mathrm{P}_{\mathrm{MC}}-\mathrm{O}_{\mathrm{MC}}\right) \text { on attitude transfer is greater for holistic thinkers } \\
\text { than for analytical thinkers. }\end{array}$ & Not supported. \\
\hline $\begin{array}{l}\mathrm{H} 11 \mathrm{~b} \text { : The effect of congruence }\left(\mathrm{P}_{\mathrm{MC}}-\mathrm{O}_{\mathrm{MC}}\right) \text { on trust transfer is greater for holistic thinkers than } \\
\text { for analytical thinkers. }\end{array}$ & $\begin{array}{l}\text { Not verified as the interaction effect } \\
\text { was not supported (see H4). }\end{array}$ \\
\hline $\begin{array}{l}\text { H12a: The effect of congruence }\left(\mathrm{O}_{\mathrm{MC}} \text { Proto) on attitude transfer is greater for analytic thinkers }\right. \\
\text { than for holistic thinkers. }\end{array}$ & Not supported. \\
\hline $\begin{array}{l}\mathrm{H} 12 \mathrm{~b} \text { : The effect of congruence }\left(\mathrm{O}_{\mathrm{MC}} \text { Proto }\right) \text { on trust transfer is greater for analytic thinkers } \\
\text { than for holistic thinkers. }\end{array}$ & Not supported. \\
\hline \multicolumn{2}{|l|}{ Re-specified Relationships } \\
\hline Direct effect of congruence $\left(\mathrm{P}_{\mathrm{MC}}-\mathrm{O}_{\mathrm{MC}}\right)$ on attitude toward online store. & Supported $(p<.001)$ \\
\hline Direct effect of congruence $\left(\mathrm{P}_{\mathrm{MC}}-\mathrm{O}_{\mathrm{MC}}\right)$ on trust in online store. & Supported $(p<.001)$ \\
\hline $\begin{array}{l}\text { Direct effect of congruence }\left(\mathrm{P}_{\mathrm{MC}}-\mathrm{O}_{\mathrm{MC}}\right) \text { on attitude toward online store is greater for holistic } \\
\text { thinkers than for analytical thinkers. }\end{array}$ & Supported $(p<.05)$ \\
\hline $\begin{array}{l}\text { Direct effect of congruence }\left(\mathrm{P}_{\mathrm{MC}}-\mathrm{O}_{\mathrm{MC}}\right) \text { on trust toward online store is greater for holistic } \\
\text { thinker than for analytical thinkers. }\end{array}$ & Not supported. \\
\hline
\end{tabular}

$\mathrm{O}_{\mathrm{MC}}$ : Online store of multi-channel retailers; $\mathrm{P}_{\mathrm{MC}}$ : Physical store of multi-channel retailers; Proto: Prototypical online store

thinkers. This finding is consistent with prior research that holds that holistic thinkers are more likely to emphasize relationship between entities than are analytic thinkers. To multi-channel retailers, this highlights the importance of leveraging the associations between the physical and online stores in markets characterized by holistic thinkers. That is, the existence of mere associative cues is especially likely to benefit multi-channel retailers while serving holistic thinkers. In addition, we find that congruence between the multi-channel retailer's physical and online store influences attitude toward and trust in the online store for both holistic and analytic thinkers. This implies that, irrespective of shoppers' thinking styles, multi-channel retailers must strive for consistency across their physical and online stores. When market-specific adaptations are executed in physical stores, similar changes must be implemented in the online stores as well to maintain image congruence. Finally, we find that congruence between the multi-channel retailer's online store and a prototypical online store influences both attitude toward and trust in the multi-channel retailer's online store for analytic thinkers and attitude toward the online store for holistic thinkers. That is, it is especially important for multi- channel retailers to identify online prototypes and benchmark their online stores against category exemplars while serving analytic thinkers. Although the total effect of congruence between the online store of the multi-channel retailer and a prototypical store is significant for only analytic thinkers, these findings suggest that multi-channel retailers must acknowledge local market preferences and expectations while designing online stores, irrespective of shoppers' thinking styles.

\section{Directions for future research and limitations}

Despite the integrative nature of the study's theoretical framework and the subsequent cross-national examination, we acknowledge that our efforts represent a starting point in the domain of research on multi-channel retailers. Several issues remain for further investigation. Consistent with our research objectives, we focused on traditional retailers who have migrated to the online retail environment. Given that some erstwhile online retailers have begun to initiate brickand-mortar operations, the proposed framework along with other context-specific variables need to be examined to verify 
whether the directionality of congruence and transference effects matter. A closer examination of the multi-channel retail environment also reveals several variations in retail branding strategies, product and brand assortments, and utilization of complementary extensions. For instance, the retailer Gap operates Gap and Baby Gap in the physical retail environment, whereas all merchandise is consolidated at Gap.com in the online environment. In contrast, the retailer Pottery Barn maintains two of its divisions, Pottery Barn and Pottery Barn Kids, as different entities in both physical and online retail environments. These examples are notably distinct from multichannel retailers who maintain just a single identity in each environment (e.g., Target and Target.com). Accordingly, in situations similar to the ones mentioned above, future researchers must investigate the role of multi-channel retailers' core and peripheral identities, sources of transference and congruence effects, and shoppers' assimilation or resolution of salient store-related attributes.

Further, we limited our focus to the influence of image congruence between (1) the physical and online stores of multichannel retailers and (2) the multi-channel retailer's online store and a prototypical online store. Future research could examine specific ways to achieve congruence, the influence of consumers' perceived congruence between the store extension's image and their self image on purchase intentions, the effects of congruence between the management's and consumers' store extension image as perceived by the management, and whether incongruence can be beneficial to multi-channel retailers in certain contexts. Additionally, the role of transference and congruence effects needs to examined across different types of multi-channel retailers (e.g., hedonic vs. functional, luxury vs. discount), product categories (e.g., low vs. high involvement), and customer contexts (business-to-consumer vs. business-tobusiness). Furthermore, the boundary conditions for transference and congruence to occur must be examined and the combinatory influence of other variables on trust in, attitude toward, and purchase intentions in online stores of multichannel retailers must be identified. In addition, although this study suggests that online stores of multi-channel retailers must be congruent with the parent physical store while assuming characteristics that are idiosyncratic to the online retail environment, future researchers can examine conditions under which congruence with one entity leads to a divergence from another and subsequent ramifications for multi-channel retailers.

Following prior research, this study employed a holistic measure for congruence and did not measure specific storerelated dimensions or attribute-by-attribute comparisons. However, in addition to holistic measures of congruence, future researchers need to investigate typical and atypical store-related attributes that influence trust in and attitude toward online stores of multi-channel retailers when shoppers draw comparisons across retail formats and prototypes. To better understand the influence of cultural differences on shoppers' evaluation of multi-channel retailer online stores, the framework needs to be tested across different countries and additional cultural dimensions. Future researchers should also explore impact of differences in thinking styles on other facets of online behavior such as social networking, blogging, and providing product feedback and recommendations, among others. From a methodological standpoint, we acknowledge that the unequal distribution of respondents in each group (i.e., holistic vs. analytic thinkers), potential cultural influences on the selection of retailers by respondents in the survey, and the cross-sectional examination of the proposed framework are potential limitations of our study that present avenues for future research.

In summary, as contemporary online shoppers possess a plethora of choices, multi-channel retailers need to develop and maintain trust in and favorable attitude toward online stores, manage the transference of trust in and attitude toward the physical stores to online stores, successfully develop and execute congruence strategies with reference to their physical stores and prototypical online stores, and pay attention to differences in thinking styles across markets. In turn, such steps could prove beneficial for enhancing purchase intentions in their online stores, competing better against other online stores, and adapting their strategies in global retail markets.

\section{Appendix}

Table 5 Reliability and validity

\begin{tabular}{lllll}
\hline Construct & $\begin{array}{l}\text { Factor Loading (completely } \\
\text { standardized) U.S./S. Korea }\end{array}$ & $\begin{array}{l}\text { Composite Reliability } \\
\text { U.S./S. Korea }\end{array}$ & $\begin{array}{l}\text { Average Variance } \\
\text { Extracted U.S./S. Korea }\end{array}$ & $\begin{array}{l}\text { Square Correlation with Other } \\
\text { Construct U.S./S. Korea }\end{array}$ \\
\hline $\begin{array}{l}\text { Trust in } \mathrm{P}_{\mathrm{MC}} \\
\text { TLb2 }\end{array}$ & $.72 / .9$ & $.81 / .87$ & $.69 / .77$ & $.35\left(\right.$ Attitude $\left(\mathrm{P}_{\mathrm{MC}}\right) / .42\left(\right.$ Attitude $\left.\left(\mathrm{P}_{\mathrm{MC}}\right)\right)$ \\
TLb3 & $.93 / .76$ & & & \\
Congruence & & $.91 / .85$ & $.71 / .59$ & $.39\left(\right.$ Attitude $\left.\left(\mathrm{O}_{\mathrm{MC}}\right)\right) / .26\left(\right.$ Trust $\left.\left(\mathrm{O}_{\mathrm{MC}}\right)\right)$
\end{tabular}

$\left(\mathrm{P}_{\mathrm{MC}}\right.$ and $\left.\mathrm{O}_{\mathrm{MC}}\right)$

COLb1 
Table 5 (continued)

\begin{tabular}{|c|c|c|c|c|}
\hline Construct & $\begin{array}{l}\text { Factor Loading (completely } \\
\text { standardized) U.S./S. Korea }\end{array}$ & $\begin{array}{l}\text { Composite Reliability } \\
\text { U.S./S. Korea }\end{array}$ & $\begin{array}{l}\text { Average Variance } \\
\text { Extracted U.S./S. Korea }\end{array}$ & $\begin{array}{l}\text { Square Correlation with Other } \\
\text { Construct U.S./S. Korea }\end{array}$ \\
\hline COLb2 & $.82 / .83$ & & & \\
\hline COLb3 & $.87 / .75$ & & & \\
\hline COLb4 & $.82 / .59$ & & & \\
\hline $\begin{array}{l}\text { Congruence } \\
\left(\mathrm{O}_{\mathrm{MC}} \text { and Proto }\right)\end{array}$ & & $.91 / .84$ & $.71 / .57$ & $\begin{array}{l}.25 \text { Congruence }\left(\mathrm{P}_{\mathrm{MC}} \text { and } \mathrm{O}_{\mathrm{MC}}\right) / .15 \\
\left(\text { Congruence }\left(\mathrm{P}_{\mathrm{MC}} \text { and } \mathrm{O}_{\mathrm{MC}}\right)\right.\end{array}$ \\
\hline COIp1 & $.92 / .84$ & & & \\
\hline COIp2 & $.67 / .70$ & & & \\
\hline COIp3 & $.92 / .74$ & & & \\
\hline COIp4 & $.83 / .75$ & & & \\
\hline $\begin{array}{l}\text { Attitude }\left(\mathrm{P}_{\mathrm{MC}}\right) \\
\text { AttL1 }\end{array}$ & $95 / .90$ & $.96 / .92$ & $.89 / .78$ & 35 (Trust in $\mathrm{P}_{\mathrm{MC}}$ ) /.42 (Trust in $\mathrm{P}_{\mathrm{MC}}$ ). \\
\hline AttL2 & $.95 / .88$ & & & \\
\hline AttL3 & $.92 / .87$ & & & \\
\hline $\begin{array}{l}\text { Trust }\left(\mathrm{O}_{\mathrm{MC}}\right) \\
\text { TO1 }\end{array}$ & $.83 / .85$ & $.87 / .89$ & $.63 / .65$ & .36 (Attitude $\left.\left(\mathrm{O}_{\mathrm{MC}}\right)\right) / .29$ (Trust in $\mathrm{P}_{\mathrm{MC}}$ ) \\
\hline TO2 & $.81 / .89$ & & & \\
\hline TO3 & $.82 / .87$ & & & \\
\hline TO5 & $.70 / .62$ & & & \\
\hline $\begin{array}{l}\text { Attitude }\left(\mathrm{O}_{\mathrm{MC}}\right) \\
\text { AttO1 }\end{array}$ & $.75 / .90$ & $.75 / .87$ & $.60 / .77$ & $\begin{array}{l}\left..39 \text { Congruence }\left(\mathrm{P}_{\mathrm{MC}} \text { and } \mathrm{O}_{\mathrm{MC}}\right)\right) / .26 \\
\left(\text { Trust }\left(\mathrm{O}_{\mathrm{MC}}\right)\right)\end{array}$ \\
\hline $\mathrm{AttO} 2$ & $.80 / .85$ & & & \\
\hline $\begin{array}{l}\text { Purchase Intentions } \\
\text { WPO2 }\end{array}$ & $.89 / .88$ & $.83 / .87$ & $.71 / .77$ & $.26\left(\right.$ Attitude $\left.\left(\mathrm{O}_{\mathrm{MC}}\right)\right) / .38\left(\right.$ Attitude $\left.\left(\mathrm{O}_{\mathrm{MC}}\right)\right)$ \\
\hline WPO3 & $.78 / .88$ & & & \\
\hline Channel Trust & & $.91 / .82$ & $.77 / .61$ & $.14\left(\right.$ Trust $\left.\left(\mathrm{O}_{\mathrm{MC}}\right)\right) / .11\left(\right.$ Trust $\left.\left(\mathrm{O}_{\mathrm{MC}}\right)\right)$ \\
\hline $\begin{array}{l}\text { CT2 } \\
\text { CT4 }\end{array}$ & $\begin{array}{l}.86 / .78 \\
.94 / .83\end{array}$ & & & \\
\hline CT5 & $\begin{array}{l}.94 / .83 \\
.84 / .73\end{array}$ & & & \\
\hline
\end{tabular}

Goodness of fit-indices: $\chi^{2}=874.03 ; \chi^{2} / \mathrm{df}=1.95 ; \mathrm{RMSEA}=0.059, \mathrm{SRMR}=0.039 ; \mathrm{GFI}=0.92$

Table 6 Measures

Trust in Physical Store $\left(\mathrm{P}_{\mathrm{MC}}\right)$

TLB1: This store is reliable

TLB2: This store is trustworthy

TLB3: This store is dependable

TLB4: This store offer secure transactions

TLB5: This store ensures the security of my information

Congruence ( $\mathrm{P}_{\mathrm{MC}}$ and $\mathrm{O}_{\mathrm{MC}}$ )

COLb1: Inconsistent-Consistent

COLb2: Different-Similar

COLb3: Unrepresentative-Representative

COLb4: Atypical-Typical

Congruence $\left(\mathrm{O}_{\mathrm{MC}}\right.$ and Proto $)$

COIp1: Inconsistent-Consistent

COIp2: Different-Similar

COIp3: Unrepresentative-Representative

COIp4: Atypical-Typical

Attitude toward the Physical Store $\left(\mathrm{P}_{\mathrm{MC}}\right)$ 
Table 6 (continued)

AttL1: Bad-Good

AttL2: Unfavorable_Favorable

AttL3: Unsatisfactory-Satisfactory

Trust in Online Store $\left(\mathrm{O}_{\mathrm{MC}}\right)$

TO1: This online store is reliable

TO2: This online store is trustworthy

TO3: This online store is dependable

TO4: This online store offer secure Web transactions

TO5: This online store ensures the security of my information

Attitude toward the Online Store $\left(\mathrm{O}_{\mathrm{MC}}\right)$

AttO1: Bad-Good

AttO2: Unfavorable-Favorable

AttO3: Unsatisfactory-Satisfactory

Purchase Intentions

WPO1: Unlikely_Likely

WPO2: Impossible_-Possible

WPO3: Improbable_-Probable

Channel Trust

CT1: Shopping in the Internet is reliable

CT2: Internet is safe for me to conduct personal business like shopping

CT3: I am comfortable making purchases on the Internet

CT4: Internet shopping can be trusted

CT5: Internet privacy structures adequately protect me from problems

Thinking Tendency

Everything in the universe is somehow related to each other

Even a small amount of change in any element in the universe can to substantial alterations in others

Any phenomenon has numerous number of causes although some of the causes are not known

Any phenomenon has numerous number of results although some the results are not known

Nothing is unrelated

It's not possible to understand the pieces without considering the whole picture

The whole is greater than the sum of its parts

Paying attention to the field is more important than paying attention to its elements

A marker of good architecture is how harmoniously it blends with other buildings around it

Sometimes, the empty space in a painting is just as important as the objects

\section{References}

Aaker, D. A., \& Keller, K. L. (1990). Consumers evaluations of brand extensions. Journal of Marketing, 54(1), 27-41.

Ahluwalia, R., \& Gurhan-Canli, Z. (2000). The effects of extensions on the family brand name: an accessibility-diagnostic. Journal of Consumer Research, 27, 371-381.

Ajzen, I., \& Fishbein, M. (1980). Understanding attitudes and predicting behavior. Upper Saddle River: Prentice Hall.

Alden, D. L., Steenkamp, J.-B. E. M., \& Batra, R. (1999). Brand positioning through advertising in Asia, North America, and Europe: the role of global consumer culture. Journal of Marketing, 63(1), 75-87.

Anderson, J. C., \& Gerbing, D. W. (1988). Structural equation modeling in practice: a review and recommended two-step approach. Psychological Bulletin, 103(3), 411-423.

Bagozzi, R. P., \& Yi, Y. (1988). On the evaluation of structural equation models. Journal of the Academy of Marketing Science, 16(1), 74-94.
Barnes, D., Hinton, M., \& Mieczkowska, S. (2004). Managing the transition from bricks-and-mortar to clicks-and-mortar: a business process perspective. Knowledge and Process Management, 11(3), 199-209.

Bollen, K. A. (1989). Structural equations with latent variable. New York: Wiley.

Bottomley, P. A., \& Holden, S. J. S. (2001). Do we really know how consumers evaluate brand extensions? Empirical generalizations based on secondary analysis of eight studies. Journal of Marketing Research, 38, 494-500.

Byrne, B. M. (1998). Structural equation modeling with LISREL, PRELIS, and SIMPLIS: Basic concepts, applications, and programming. Lawrence Erlbaum, Mahwah: Lawrence Erlbaum.

Campbell, D. T. (1958). Common fate, similarity, and other indices of the status of aggregates of persons as social entities. Behavioral Science, 3, 14-25.

Chiu, L.-H. (1972). A cross-cultural comparison of cognitive styles in Chinese and American Children. International Journal of Psychology, 7(4), 235-242. 
Choi, J., \& Park, J. (2006). Multichannel retailing in Korea: effects of shopping orientations and information seeking patterns on channel choice behavior. International Journal of Retail and Distribution Management, 34(8), 577-596.

Choi, I., Nisbett, R. E., \& Smith, E. E. (1997). Culture, category salience, and inductive reasoning. Cognition, 65(1), 15-32.

Choi, I., Koo, M., \& Choi, J. A. (2007). Individual differences in analytic versus holistic thinking. Personality and Social Psychology Bulletin, 33(5), 691-705.

Churchill, G. A., Jr., \& Peter, J. P. (1984). Research design effects on the reliability of rating scales: a meta-analysis. Journal of Marketing Research, 21(4), 360-375.

Cortina, J. M., Chen, G., \& Dunlap, W. P. (2001). Testing interaction effects in LISREL: examination and illustration of available procedures. Organizational Research Methods, 4(4), 324-360.

Dacin, P. A., \& Smith, D. C. (1994). The effect of brand portfolio characteristics on consumer evaluations of brand extensions. Journal of Marketing Research, 31(2), 229-242.

Doney, P. M., Cannon, J. P., \& Mullen, M. R. (1998). Understanding the influence of national culture on the development of trust. Academy of Management Review, 23(3), 601-620.

Evans, K. R., Christiansen, T., \& Gill, J. D. (1996). The impact of social influence and role expectations on shopping center patronage intentions. Journal of the Academy of Marketing Science, 24(3), 208-218.

Fiske, S. T., \& Linville, P. W. (1980). What does the schema concept buy us? Personality and Social Psychology Bulletin, 6(4), 543-557.

Fiske, S. T., \& Pavelchak, M. A. (1986). Category-based versus piecemeal-based affective responses: Developments in schema triggered affect. In R. M. Sorrentiono \& E. T. Higgins (Eds.), The handbook of motivation and cognition: Foundation of social behavior (pp. 167-203). New York: Guilford Press.

Fornell, C., \& Larcker, D. F. (1981). Evaluating structural equation models with observable variables and measurement error. Journal of Marketing Research, 18(1), 39-50.

Goldstein, A. G., \& Chance, J. E. (1980). Memory for faces and schema theory. The Journal of Psychology, 105(1), 47-59.

Grewal, D., Krishnan, R., Baker, J., \& Borin, N. (1998). The effect of store name, brand name, and price discounts on consumers' evaluations and purchase intentions. Journal of Retailing, 74(3), 331-352.

Ha, S., \& Stoel, L. (2009). Consumer e-shopping acceptance: antecedents in a technology acceptance model. Journal of Business Research, 62(5), 565-571.

Hancock, G. R., \& Mueller, R. O. (2006). Structural equations: A second course. Greenwich: Information Age Publishing, Inc.

Hofstede, G. (1997). Cultures and organizations: Software of the mind. New York: The McGraw-Hill Companies, Inc.

Hu, H., \& Jasper, C. R. (2007). A cross-cultural examination of the effects of social perception styles on store image formation. Journal of Business Research, 60, 222-230.

Internet Retailer (2010). The top 500 list. Retrieved May 10, 2010 from http://www.internetretailer.com/top500/list/.

Jarvenpaa, S. L., \& Tractinsky, N. (1999). Consumer trust in an internet store: a cross-cultural validation. Journal of ComputerMediated Communication, 5(2), 1-33.

Ji, L., \& Nisbett, R. E. (2001). Culture, language, and categories. Unpublished manuscript, University of Michigan.

John, D. R., Loken, B., \& Joiner, C. (1998). The negative impact of extensions: can flagship products be diluted? Journal of Marketing, 62(1), 19-32.

Kenny, D. A., \& Judd, C. M. (1984). Estimating the nonlinear and interactive effects of latent variables. Psychological Bulletin, 96(1), 210-210.

Konus, U., Verhoef, P. C., \& Neslin, S. A. (2008). Multichannel shopper segments and their covariates. Journal of Retailing, 84 (4), 398-413.

Kwak, H., Zinkhan, G. M., \& Lester Roushanzamir, E. P. (2004). Compulsive comorbidity and its psychological antecedents: a cross-cultural comparison between the US and South Korea. Journal of Consumer Marketing, 21(6), 418-434.

Kwon, W.-S., \& Lennon, S. J. (2009a). Reciprocal effects between multichannel retailers' offline and online brand images. Journal of Retailing, 85(3), 376-390.

Kwon, W.-S., \& Lennon, S. J. (2009b). What induces online loyalty? Online versus offline brand images. Journal of Business Research, 62(5), 557-564.

Lee, M. S., Geistfeld, L. V., \& Stoel, L. (2007). Cultural differences between Korean and American apparel websites. Journal of Fashion Marketing and Management, 11(4), 511-528.

Lindell, M. K., \& Whitney, D. J. (2001). Accounting for common method variance in cross-sectional research designs. The Journal of Applied Psychology, 86(1), 114-121.

Loken, B., \& Ward, J. (1990). Alternative approaches to understanding the determinants of typicality. Journal of Consumer Research., 17 (2), 111-126.

Mao, H., \& Krishnan, H. S. (2006). Effect of prototype and exemplar fit on brand extension evaluations: a two-process contingency model. Journal of Consumer Research, 33(1), 41-49.

Masuda, T., \& Nisbett, R. E. (2001). Attending holistically versus analytically: comparing the context sensitivity of Japanese and Americans. Journal of Personality and Social Psychology, 81(5), 922-934.

Mazursky, D., \& Jacoby, J. (1986). Exploring the development of store images. Journal of Retailing, 62, 145-165.

McKnight, D. H., Choudhury, V., \& Kacmar, C. (2002). Developing and validating trust measures for e-commerce: An integrative typology. Information Systems Research, 13(3), 334-359.

Monga, A. B., \& John, D. R. (2007). Cultural differences in brand extension evaluation: The influence of analytic versus holistic thinking. Journal of Consumer Research, 33, 529-536.

National Retail Federation (2010). 2009 favorite 50 retailers. Retrieved May 10, 2010 from http://www.stores.org/2009/Favorite-50-Retailers

Ng, S., \& Houston, M. J. (2006). Exemplars or beliefs? The impact of self-view on the nature and relative influence of brand associations. Journal of Consumer Research, 32(4), 519-529.

Nielsen/NetRatings (2005). Online retail report card: highest conversion rates amongst non-brick-and-mortar retailers, according to Nielsen/NetRatings Megaview online retail. Retrieved from www.netratings.com/pr/pr 050407.pdf.

Nielsen/Nielsen Online (2008). Over 875 million consumers have shopped online-The number of internet shoppers up $40 \%$ in two years. The Nielsen Company. Retrieved from http://www.nielsen. com/media/2008/pr_080128b.html.

Nisbett, R. E., Peng, K., Choi, I., \& Norenzayan, A. (2001). Culture and systems of thought: holistic versus analytical cognition. Psychological Review, 108(2), 291-310.

Norenzayan, A., Nisbett, R. E., Smith, E. E., \& Kim, B. J. (2000). Rules vs. similarity as a basis for reasoning and judgment in East and West. Unpublished manuscript, University of Illinois.

Page, C., \& Lepkowska-White, E. (2002). Web equity: a framework for building consumer value in online companies. Journal of Consumer Marketing, 19(3), 231-248.

Ping, R. A., Jr. (1995). A parsimonious estimating technique for interaction and quadratic latent variables. Journal of Marketing Research, 32(3), 336-347.

Podsakoff, P. M., \& Organ, D. W. (1986). Self-reports in organizational research: problems and prospects. Journal of Management, 12(4), 531-544.

Podsakoff, P. M., Todor, W. D., Grove, R. A., \& Huber, V. L. (1984). Situational moderators of leader reward and punishment behavior: fact or fiction? Organizational Behavior and Human Performance, $34,21-63$.

Podsakoff, P. M., MacKenzie, S. B., Lee, J. Y., \& Podsakoff, N. P. (2003). Common method biases in behavioral research: a critical 
review of the literature and recommended remedies. The Journal of Applied Psychology, 88(5), 879-903.

Rafiq, M., \& Fulford, H. (2005). Loyalty transfer from off-line to online stores in the UK grocery industry. International Journal of Retail and Distribution Management, 33(6/7), 444-460.

Ranganathan, C., Goode, V., \& Ramaprasad, A. (2003). Managing the transition to bricks and clicks. Communications of the ACM, 46 (12), 308-316.

Rigby, E. (2007). Online trick turn browser to sales clicks. Financial Times, May 18, page 3.

Schlosser, A. E., White, T. B., \& Lloyd, S. M. (2006). Converting web site visitors into buyers: how web site investment increases consumer trusting beliefs and online purchase intentions. Journal of Marketing, 70(2), 133-48.

Shim, S., Eastlick, M. A., Lotz, S. L., \& Warrington, P. (2001). An online prepurchase intentions model: the role of intentions to search. Journal of Retailing, 77, 397-416.

Singh, J. (1995). Measurement issues in cross-national research. Journal of International Business Studies, 26(3), 597-619.

Sirgy, J. M., \& Samli, C. A. (1985). A path analytic model of store loyalty involving self-concept, store image, geographic loyalty, and socioeconomic status. Journal of the Academy of Marketing Science, 13, 265-291.

Stewart, K. J. (2003). Trust transfer on the World Wide Web. Organization Science, 14(1), 5-17.

Strub, P. J., \& Priest, T. B. (1976). Two patterns of establishing trust: the marijuana user. Sociological Focus, 9(4), 399-411.
Sujan, M. (1985). Consumer knowledge: effects on evaluation strategies mediating consumer judgments. Journal of Consumer Research, 12, 31-46.

Suri, R., Manchada, R. V., \& Lee, S. (2004). Comparing the effectiveness of fixed and discounted prices in the US and South Korea. International Journal of Retail and Distribution Management, 32(6/7), 328-336

Teltzrow, M., Meyer, B., \& Lenz, H. J. (2007). Multichannel consumer perceptions. Journal of Electronic Commerce, 8(1), 18-31.

Walther, E. (2002). Guilty by mere association: evaluative conditioning and the spreading attitude effect. Journal of Personality and Social Psychology, 82, 919-934.

Walther, E., \& Grigoriadis, S. (2004). Why sad people like shoes better: the influence of mood on the evaluative conditioning of consumer attitudes. Psychology and Marketing, 21, 755-773.

Walther, E., \& Langer, T. (2008). Attitude formation and change through association: An evaluative conditioning account. In W. D. Crano \& R. Prislin (Eds.), Attitudes and attitude change (pp. 87-109). New York: Psychology.

Walton, G., \& Bower, T. G. R. (1993). Newborns form 'prototypes' in less than 1 minute. Psychological Science, 4(3), 203-205.

Wang, S., Beatty, S. E., \& Mothersbaugh, D. L. (2009). Congruity's role in website attitude formation. Journal of Business Research, 66(6), 609-615.

Yoo, B., \& Donthu, N. (2002). Testing cross-cultural invariance of the brand equity creation process. The Journal of Product and Brand Management, 11(6/7), 380-398. 